\title{
Myogenic differentiation potential of human tonsil-derived mesenchymal stem cells and their potential for use to promote skeletal muscle regeneration
}

\author{
SAEYOUNG PARK ${ }^{1}$, YOONYOUNG CHOI ${ }^{1}$, NAMHEE JUNG ${ }^{1}$, YEONSIL YU ${ }^{2}$, KYUNG-HA RYU $^{3}$, \\ HAN SU KIM ${ }^{4}$, INHO JO${ }^{2}$, BYUNG-OK $\mathrm{CHOI}^{5}$ and SUNG-CHUL JUNG ${ }^{1}$
}

\begin{abstract}
Departments of ${ }^{1}$ Biochemistry, ${ }^{2}$ Molecular Medicine, ${ }^{3}$ Pediatrics, and ${ }^{4}$ Otorhinolaryngology - Head and Neck Surgery, School of Medicine, Ewha Womans University, Seoul 07985; ${ }^{5}$ Department of Neurology, Samsung Medical Center, Sungkyunkwan University, Seoul 06351, Republic of Korea
\end{abstract}

Received November 7, 2015; Accepted March 11, 2016

DOI: $10.3892 / \mathrm{ijmm} .2016 .2536$

\begin{abstract}
Stem cells are regarded as an important source of cells which may be used to promote the regeneration of skeletal muscle (SKM) which has been damaged due to defects in the organization of muscle tissue caused by congenital diseases, trauma or tumor removal. In particular, mesenchymal stem cells (MSCs), which require less invasive harvesting techniques, represent a valuable source of cells for stem cell therapy. In the present study, we demonstrated that human tonsil-derived MSCs (T-MSCs) may differentiate into myogenic cells in vitro and that the transplantation of myoblasts and myocytes generated from human T-MSCs mediates the recovery of muscle function in vivo. In order to induce myogenic differentiation, the T-MSC-derived spheres were cultured in Dulbecco's modified Eagle's medium/nutrient mixture F-12 (DMEM/F-12) supplemented with $1 \mathrm{ng} / \mathrm{ml}$ transforming growth factor- $\beta$, non-essential amino acids and insulin-transferrin-selenium for 4 days followed by culture in myogenic induction medium [low-glucose DMEM containing 2\% fetal bovine serum (FBS) and $10 \mathrm{ng} / \mathrm{ml}$ insulin-like growth factor 1 (IGF1)] for 14 days. The T-MSCs sequentially differentiated into myoblasts and skeletal myocytes, as evidenced by the increased expression of skeletal myogenesis-related markers [including $\alpha$-actinin, troponin I type 1 (TNNI1) and myogenin] and the formation of myotubes in vitro. The in situ transplantation of T-MSCs into mice with a partial myectomy of the right gastrocnemius muscle enhanced muscle function, as demonstrated by gait assessment (footprint analysis), and restored the shape of SKM without forming teratomas. Thus, T-MSCs may differentiate into myogenic cells and effectively regenerate SKM following
\end{abstract}

Correspondence to: Dr Sung-Chul Jung, Department of Biochemistry, School of Medicine, Ewha Womans University, 1071 Anyangcheon-ro, Yangcheon-gu, Seoul 07985, Republic of Korea

E-mail: jungsc@ewha.ac.kr

Key words: human tonsil-derived mesenchymal stem cells, skeletal muscle, differentiation, regeneration, stem cell therapy injury. These results demonstrate the therapeutic potential of T-MSCs to promote SKM regeneration following injury.

\section{Introduction}

A number of studies have been performed using stem cells in order to treat muscle-related diseases in which the organization of muscle tissue is adversely affected by congenital hereditary muscle defects, loss of muscle mass, trauma or tumor removal (1-5). Previous studies have reported the transplantation of muscle stem cell-derived myoblasts or myogenic cells in models of muscle injury (6-8). However, the main issue which researchers confront is the fact that it is difficult to obtain the required numbers of cells for transplantation to a site of injury due to the cultivation period required in order to generate muscle stem cells. Several groups have reported the differentiation of embryonic stem (ES) cells and induced pluripotent stem (iPS) cells into myogenic cells $(4,9,10)$. However, there are major obstacles to the clinical use of ES and iPS cells, including teratoma formation and the rejection of transplanted cells by the immune system. Compared with these cells, mesenchymal stem cells (MSCs), which have the ability to regulate the immune system and do not form teratomas, may be isolated from various sources, including bone marrow (11), adipose tissue (12), umbilical cord blood (13), amniotic fluid (14), the placenta (15), dental pulp (16), the tonsils (17) and urine (1). For these reasons, MSCs have been recognized as a valuable source of cells which may be used to propagate myogenic cells according to the protocols for differentiation. Several studies examining the differentiation of MSCs into myogenic cells have been reported the use of MSCs derived from adipose tissue, bone marrow, the placenta, amniotic fluid, umbilical cord blood and urine $(1,2,11-14,18)$.

The tonsils are a newly identified source of MSCs which may have potential therapeutic applications. Tonsil-derived MSCs (T-MSCs) readily differentiate into cells of the mesodermal lineage, including fat, cartilage and bone cells, and into cells of the endodermal lineage, including hepatocytes (19-21). T-MSCs also exhibit similar immunosuppressive properties to bone marrow-derived MSCs and adipose tissue-derived MSCs (22,23). As tonsillar tissues are discarded after surgery, 
the isolation of stem cells from these discarded tissues is also a valuable means of recycling human tissue for stem cell therapy $(23,24)$.

Skeletal muscle (SKM) possesses the ability to grow in response to increased workload or to repair itself in the case of injury. The postnatal growth, repair and maintenance of muscle fibers depend on a population of muscle stem cells (25) that are located beneath the basal membrane of muscle fibers. However, an extensive muscle injury may prevent complete regeneration, particularly in terms of functional recovery. Severe lesions associated with the loss of healthy muscular tissue and the development of fibrous scar tissue, as well as irreversible muscular atrophy following long-term peripheral nerve injury are examples of situations in which regeneration is limited (5). As an alternative approach to the regeneration of damaged SKM, and considered to be the optimal treatment for certain traumatic or degenerative diseases (26), the transplantation of T-MSC-derived myogenic cells is a suitable method for limiting the atrophy of the affected muscles, and may even lead to myocyte regeneration and reduced motor deficits.

In the present study, we demonstrated that T-MSCs may differentiate into myogenic cells in vitro and that the transplantation of the myoblasts and myocytes generated from human T-MSCs mediates the recovery of muscle function following injury in vivo. Immunocy tochemistry, reverse transcriptionpolymerase chain reaction (RT-PCR), and western blot analysis confirmed the development of T-MSC-derived myogenic cells in vitro. Furthermore, the in situ transplantation of T-MSCs into mice with a partial myectomy of the right gastrocnemius muscle, led to enhanced muscle function, as demonstrated by gait assessment (footprint analysis). These results suggest that human tonsils are a promising source of stem cells and that T-MSCs may be used to promote the regeneration of SKM following injury.

\section{Materials and methods}

Ethics statement. The Institutional Review Board of Ewha Womans University, Mokdong Hospital (Seoul, Korea) approved all the experimental procedures used in this study (approval no. ECT-11-53-02). Informed written consent was obtained from each patient and/or their legal representatives prior to obtaining the tissue samples. Animal care and experimental procedures were approved by the Institutional Animal Care and Use Committee at Ewha Womans University School of Medicine(ESM no. 14-0285), and all experiments were performed in accordance with approved guidelines and regulations, namely the guidelines of the Korean Ministry of Health and Welfare, the Animal Care Guidelines of the Ewha Womans University School of Medicine, and the National Research Council (US) Guide for the Care and Use of Laboratory Animals (27).

Animals. Seven-week-old male C57BL/6 mice $(\mathrm{n}=40$; weighing, 21-24 g; Dae-Han Biolink Co, Ltd, Eumseong, Korea) housed at $21 \pm 2^{\circ} \mathrm{C}$ and $55 \pm 5 \%$ humidity under a $12 \mathrm{~h}$ light/dark cycle, and supplied with food and water ad libitum were used for all the experiments. The mice were fed an autoclaved diet and also provided with water ad libitum. All the mice were treated in accordance with the above-mentioned guidelines. A minimum of 10 age-matched mice were used for each group. The animals were sacrificed by $\mathrm{CO}_{2}$ inhalation.
Isolation of T-MSCs. The isolation of T-MSCs from tonsillar tissue was performed as previously described $(17,28)$. Briefly, tonsillar tissues were collected from patients during tonsillectomy, and subsequently minced and digested in Dulbecco's modified Eagle's medium (DMEM) containing $210 \mathrm{U} / \mathrm{ml}$ collagenase type I (both from Invitrogen, Carlsbad, CA, USA) and DNase (10 $\mu \mathrm{g} / \mathrm{ml}$, Sigma-Aldrich, St. Louis, MO, USA). After the cells were passed through a cell strainer (BD Biosciences, San Jose, CA, USA), mononuclear cells were obtained by FicollPaque (GE Healthcare, Chalfont St. Giles, UK) density gradient centrifugation. The cells were cultured for $48 \mathrm{~h}$ at $37^{\circ} \mathrm{C}$ in low-glucose DMEM containing 10\% fetal bovine serum (FBS; Invitrogen) and $1 \%$ penicillin/streptomycin (Sigma-Aldrich) in a humidified chamber with $5 \% \mathrm{CO}_{2}$. This was followed by the removal of non-adherent cells and the T-MSCs were cultured in fresh medium. These freshly cultured cells were expanded over 3-5 passages, a process which took approximately 4 weeks.

Adipogenic, osteogenic and chondrogenic differentiation of T-MSCs. The mesodermal differentiation of T-MSCs was induced as previously described (17) with minor modifications. Briefly, to induce adipogenic differentiation, the T-MSCs were cultured in commercially available adipogenic medium (Invitrogen) for 3 weeks. Subsequently, the cells were washed twice with phosphate-buffered saline (PBS), fixed in $4 \%$ paraformaldehyde (PFA) for $15 \mathrm{~min}$ at room temperature, then washed with PBS and stained with $2 \%$ Oil Red O (Sigma-Aldrich) for $1 \mathrm{~h}$ at room temperature. The T-MSCs were washed again with PBS. The intracellular lipid droplets were visualized under a microscope (IX2-SLP; Olympus, Tokyo, Japan). To quantify lipid accumulation, Oil Red $\mathrm{O}$ deposited in the cells was eluted with $100 \%$ isopropanol for $10 \mathrm{~min}$ and the absorbance of the eluting solution was measured at a wavelength of $540 \mathrm{~nm}$ using an ELISA microplate reader (BN03269, VersaMax; Molecular Devices, San Jose, CA, USA).

To induce osteogenic differentiation, the T-MSCs were cultured in commercially available osteogenic medium (Invitrogen) for 3 weeks. Thereafter, the cells were washed twice with PBS, fixed in 4\% PFA for $15 \mathrm{~min}$ at room temperature and stained with $2 \%$ Alizarin Red S (SigmaAldrich) for $1 \mathrm{~h}$. After rinsing the cells 2 more times with PBS, the extracellular matrix calcification was visualized under a phase-contrast microscope (IX2-SLP; Olympus). To quantify calcium deposition, the cells were incubated with $10 \%$ cetylpyridinium chloride for 10 min to extract the Alizarin Red S. The eluate was collected and absorbance was measured at a wavelength of $570 \mathrm{~nm}$ using an ELISA microplate reader (BN03269, VersaMax; Molecular Devices).

To induce chondrogenic differentiation, the T-MSCs were stimulated for 3 weeks in commercially available chondrogenesis-inducing medium (Invitrogen). Thereafter, the cells were rinsed with PBS and fixed in 4\% PFA for 15 min at room temperature. After washing, the cells were stained with $1 \%$ Alcian blue (Sigma-Aldrich) for $1 \mathrm{~h}$ at room temperature, and the excess dye was removed. Subsequently, the cells were rinsed again with $0.1 \mathrm{~N} \mathrm{HCl}$, and the chondrogenic cells were visualized under a phase-contrast microscope (IX2-SLP; Olympus). To quantify the intensity of Alcian blue staining, the cells were solubilized with $400 \mu \mathrm{l}$ of $1 \%$ SDS. The absorbance was read at a wavelength of $605 \mathrm{~nm}$. 
Myogenic differentiation. To induce the myogenic differentiation of the T-MSCs, $3-4 \times 10^{6}$ cells were plated in a 15-cm Petri dish in low-glucose DMEM supplemented with $10 \%$ FBS. At 1-3 days, the cells spontaneously aggregated to form spheres $50-100 \mu \mathrm{m}$ in diameter. Once the spheres had formed, the medium was replaced with DMEM/nutrient mixture F-12 (DMEM/F-12; Invitrogen) supplemented with $1 \mathrm{ng} / \mathrm{ml}$ transforming growth factor- $\beta$ (TGF- $\beta$; R\&D Systems, Minneapolis, MN, USA), non-essential amino acids (NEAA; Invitrogen) and insulin-transferrin-selenium (ITS; Gibco Life Technologies, Grand Island, NY, USA) for a further 4 days in order to allow differentiation into myoblasts. The T-MSCs grew out of the spheres when transferred to a collagen-coated dish in the above mentioned myoblast differentiation medium, and formed a rosette-like spread. To induce terminal differentiation into myocytes, the myoblasts were cultured for 2 weeks in myogenic induction medium, which consisted of low-glucose DMEM containing $10 \mathrm{ng} / \mathrm{ml}$ insulin-like growth factor 1 (IGF1; R\&D Systems) and 2\% FBS (Fig. 2D).

$R T$-PCR. Total RNA was extracted from the cells using an RNeasy Mini kit (Qiagen, Germantown, MD, USA). Complementary DNA (cDNA) was synthesized using SuperScript II (Invitrogen) and oligo-(dT)20 primers at $42^{\circ} \mathrm{C}$ for $1 \mathrm{~h}$ followed by incubation at $72^{\circ} \mathrm{C}$ for $15 \mathrm{~min}$. Target sequences from the cDNA were amplified using premixed kits (Bioneer, Daejeon, Korea) under the following conditions: initial denaturation at $95^{\circ} \mathrm{C}$ for 5 min followed by 35 cycles of denaturation at $95^{\circ} \mathrm{C}$ for $30 \mathrm{sec}$, annealing at $45-60^{\circ} \mathrm{C}$ for $45 \mathrm{sec}$ and extension at $72^{\circ} \mathrm{C}$ for $44 \mathrm{sec}$. Normalized amounts of products were separated on a $1.5 \%$ agarose gel and visualized by ethidium bromide staining. The sequences of the forward and reverse primers used were as follows: Krüppel-like factor 4 (Klf4) forward, 5'-CCCGATCAGATGCAGCCGCAAGTC-3' and reverse, 5'-CTGGCTGGGCTCCTTCCCTCATCG-3'; RexI forward, 5'-CAGATCCTAAACAGCTCGCA-3' and reverse, 5'-GCGTACGCAAATTAAAGTCC-3'; activin forward, 5'-AGAGCGACCTCACAGCCGTGCTGG-3' and reverse, 5'-CCGAGGTAGTGCCGTTGACCGACCT-3'; paired box 7 (Pax7) forward, 5'-CACTGTGACCGAAGCACTGT-3' and reverse, 5'-GTCAGGTTCCGACTCCACAT-3'; myogenic factor $6(M y f 6)$ forward, 5'-AGGAACCCAGACCGAA AAGT-3' and reverse, 5'-TTGAACATGGCACAAAAGGA-3'; myogenin forward, 5'-GTCTTCGCCGGGCATCCTTG-3' and reverse, 5'-GAGCTGGGGCATACACGAGGGG-3'; dystrophin forward, 5'-ACCACCTCTGACCCTACACG-3' and reverse, 5'-GCAATGTGTCCTCAGCAGAA-3'; and glyceraldehyde 3-phosphate dehydrogenase $(G A P D H)$ forward, 5'-TGGTAT CGTGGAAGGACTCA-3' and reverse, 5'-CCTGCTTCACC ACCTTCTTG-3'.

Immunocytochemistry. The cells grown on coverslips were fixed in 4\% (v/v) PFA (Sigma-Aldrich) for $15 \mathrm{~min}$ at room temperature or overnight at $4^{\circ} \mathrm{C}$. After rinsing in PBS, the fixed cells were permeabilized and non-specific epitopes were blocked using $2 \%$ bovine serum albumin (Bovogen Biologicals, East Keilor, VIC, Australia) in 0.1\% Tween-20/ PBS, followed by incubation in the diluted primary antibody for $1 \mathrm{~h}$ at room temperature or overnight at $4^{\circ} \mathrm{C}$. Following 3 washes in PBS, the samples were incubated for $1 \mathrm{~h}$ at room temperature with secondary antibodies diluted in PBS. The prepared samples were then mounted using Vectashield mounting medium containing 4',6-diamidino2-phenylindole (DAPI; Vector Laboratories, Burlingame, CA, USA) and images were captured under a fluorescence microscope (Nikon Corp., Tokyo, Japan). The manufacturers and catalog numbers (Cat. no.) of the antibodies employed were as follows: mouse anti-CD34 (Cat. no. SC-74499; Santa Cruz Biotechnology, Inc., Dallas, TX, USA), rabbit anti-Pax7 (Cat. no. ab187339; Abcam, Cambridge, UK), mouse anti-desmin (Cat. no. D1033; Sigma-Aldrich), rabbit anti-dystrophin (Cat. no. ab15277; Abcam), mouse anti-myosin heavy chain (MHC, Cat. no. MAB4470; R\&D Systems), rabbit anti- $\alpha$-actinin (Cat. no. PA5-17308; Thermo Fisher Scientific, Scoresby, VIC, Australia), rabbit anti-troponin I type 1 (TNNI1; Cat. no. NBP1-90923; Novus Biologicals, Littleton, CO, USA), mouse anti-myogenin (Cat. no. ab1835; Abcam) (primary antibodies), and tetramethylrhodamine (TRITC)-conjugated Alexa-568 goat anti-mouse IgG (Cat. no. A-11031), fluorescein isothinocyanate (FITC)-conjugated Alexa-568 goat anti-mouse IgG (Cat. no. A-11004), and TRITC-conjugated Alexa-568 goat anti-rabbit IgG (Cat. no. A-11011) (all from Life Technologies) (secondary antibodies).

Western blot analysis. The protein concentrations were determined using Bradford assay reagent (Bio-Rad Laboratories, Hercules, CA, USA) after lysing the cells in Pro-Prep buffer (iNtRON Biotechnology, Seongnam, Korea) supplemented with phosphatase inhibitor cocktail solution (Dawinbio, Hanam, Korea). The cells were washed with ice-cold PBS and exposed to Pro-Prep buffer supplemented with phosphatase inhibitor cocktail solution for $30 \mathrm{~min}$ on ice. Insoluble material was removed by centrifugation at $12,000 \mathrm{x}$ g for $10 \mathrm{~min}$ at $4^{\circ} \mathrm{C}$. The proteins $(30-80 \mu \mathrm{g})$ were separated by $7.5-13.5 \%$ sodium dodecyl sulfate-polyacrylamide gel electrophoresis and transferred onto polyvinylidene fluoride or nitrocellulose membranes (Millipore, Billerica, MA, USA). The membranes were blocked with 5\% skim milk in Tris-buffered saline containing $0.1 \%$ Tween-20 (TBST) for $2 \mathrm{~h}$ at room temperature. The blots were then incubated with primary antibodies overnight at $4^{\circ} \mathrm{C}$. The antibodies used for western blot analysis were rabbit anti- $\alpha$-actinin (Cat. no. PA5-17308) (both from Thermo Fisher Scientific), mouse anti-desmin (Cat. no. D1033) and mouse anti- $\alpha$-SMA (Cat. no. A2547) (both from Sigma-Aldrich), rabbit anti-TNNI1 (Cat. no. NBP1-90923; Novus Biologicals), and mouse anti-myogenin (Cat. no. ab1835; Abcam). The blots were washed 3 times for 5 min with TBST and then incubated with horseradish peroxidase-labeled secondary antibody for $1 \mathrm{~h}$ at room temperature. Goat anti-mouse $\operatorname{IgG}(1: 2,500$, Cat. no. SC-2005; Santa Cruz Biotechnology) and goat antirabbit IgG (1:2,500, Cat. no. 7074; Cell Signaling Technology, Beverley, MA, USA) were used as the secondary antibodies. After additional washes, signals were detected using a WESTSAVE Gold western blot detection kit (Young In Frontier Co., Ltd., Seoul, Korea). The protein signals were visualized by exposing the membranes to a luminescent image analyzer (LAS-3000; Fujifilm, Tokyo, Japan). The level of expression of each protein was normalized to that of GAPDH (Sigma-Aldrich). The results were quantified using ImageJ software (1.48 V; Wayne Rasband, NIH, USA). 

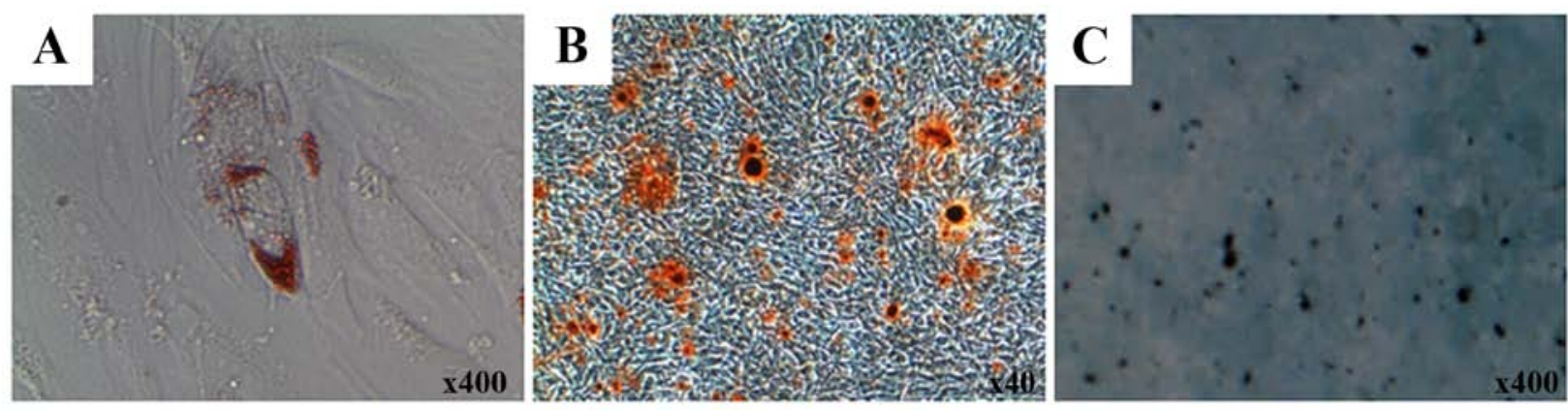

Figure 1. Establishment of the differentiation potential of tonsil-derived mesenchymal stem cells (T-MSCs) toward mesodermal lineages. T-MSCs readily differentiated into (A) adipocytes, (B) osteoblasts and (C) chondrocytes, as determined by Oil Red O, Alizarin Red S staining, and Alcian blue, respectively.

Transplantation of T-MSCs into mice. The surgeries were performed under general anesthesia using a mixture of Zoletil 50 (Virbac, Carros, France) and Rompun (Bayer Korea, Seoul, Korea), at a 3:1 ratio, administered $1 \mathrm{ml} / \mathrm{kg}$ intraperitoneally. To establish a model of myectomy, we removed a $0.5 \times 1.0 \mathrm{~cm}$ fraction $(40-60 \mathrm{mg})$ of the gastrocnemius muscle from each mouse in order to create a defect, as previously described (5). This was accomplished by lacerating the lateral side of the right muscle with a no. 9 scalpel blade. Forty-eight hours after inducing muscle injury, $1 \times 10^{6} \mathrm{~T}-\mathrm{MSC}$ /T-MSC-derived myocytes in PBS (100 $\mu$ l each) or PBS alone (100 $\mu$ l, used as the vehicle) were injected intramuscularly into the midpoint of the damaged part of the gastrocnemius muscle. The PBS-treated mice served as the vehicle-treated group (vehicle). A group of normal (uninjured) mice was also used as a control. In total, there were 5 groups with 8 mice/group: the normal group, the injured group, the vehicle-treated group, the T-MSC-injected group and the T-MSC-myocyte-injected group. The mice were sacrificed in order to obtain tissues for immunohistochemical analysis at $48 \mathrm{~h}, 7$ days, and at 4 and 8 weeks post-transplantation.

Immunohistochemistry. For immunohistochemistry, mouse gastrocnemius muscles were fixed in $10 \%$ formaldehyde. Following approximately $24 \mathrm{~h}$ of fixation at $4^{\circ} \mathrm{C}$, the muscles were washed in PBS at room temperature. The washed muscles were dehydrated in a graded ethanol series, cleared in xylene, and embedded in paraffin wax. The blocks were sectioned into $5-\mu \mathrm{m}$ thick serial sections. The sectioned tissues were placed onto a microscope slide. Non-specific epitopes were blocked using 3\% bovine serum albumin in $0.1 \%$ Triton X-100/PBS followed by incubation with the appropriate primary antibody for $1 \mathrm{~h}$ at room temperature. Following 3 washes in $0.1 \%$ Triton $\mathrm{X}-100 / \mathrm{PBS}$, the samples were incubated with secondary antibodies for $1 \mathrm{~h}$ at room temperature or at $4^{\circ} \mathrm{Covernight}$. The tissues were mounted using Vectashield mounting medium containing DAPI (Vector Laboratories) and images were captured under a fluorescence microscope (Nikon Corp.). The manufacturers and catalog numbers of the antibodies employed were as follows: rabbit anti-dystrophin (Cat. no. ab15277; Abcam), mouse anti- $\alpha$-SMA (Cat. no. A2547; Sigma-Aldrich), rabbit anti-TNNI1 (Cat. no. NBP1-90923; Novus Biologicals) (primary antibodies), Alexa-568 goat anti-mouse IgG (Cat. no. A-11031), and Alexa-568 goat anti-rabbit IgG (Cat. no. A-11057) (both from Life Technologies) (secondary antibodies).
Gait assessment by footprint analysis. The bottom of each hind foot of each mouse was coated with non-toxic ink, and the mouse was allowed to walk through a small tunnel on white paper. Stride length (distance between the 2 rear paw prints) was measured as previously described $(29,30)$ at 1,2,3, 4 and 8 weeks after transplantation. The stride lengths of the mice in the normal, injured, vehicle-treated and T-MSC-myocyte-transplanted groups were then compared using an unpaired Duncan's test.

Morphological assessment of regeneration. Photographic images were obtained of the gastrocnemius muscle from mice in the injured group and the transplantation groups using a camera (Galaxy Note 2 SHV-E250S camera; Samsung, Seoul, Korea) and stored as 8 megapixel Back-illuminated sensor. The criteria for the assessment of morphological regeneration was the disappearance of any sign of injury and that the wound was filled with muscle.

Statistical Analysis. The results are presented as the means \pm standard error of the mean (SEM). Statistical comparisons were performed using Duncan's test with GraphPad Prism software 5.01 (GraphPad Software, Inc., San Diego, CA, USA) to identify significant differences between groups. A P-value $<0.01-0.05$ was considered to indicate a statistically significant difference. All the experiments were performed at least 3 times.

\section{Results}

Myogenic cells derived from T-MSCs. It has been previously reported that T-MSCs possess the characteristics of MSCs $(17,21)$. In our study, T-MSCs were found to differentiate into 3 different cell types, namely adipocytes, osteocytes and chondrocytes (Fig. 1). To induce myogenic differentiation, the T-MSCs (Fig. 2A) were allowed to form spheres of approximately $50-100 \mu \mathrm{m}$ in diameter on the Petri dish (Fig. 2B). The T-MSCs grew out of the spheres when transferred to a collagencoated dish in replating medium, and formed a rosette-like spread (Fig. 2C). The plated cells were cultured for 2 weeks to allow terminal differentiation into myocytes (Fig. 2D). The cultivation of the cells in vitro for up to 2 weeks in low-glucose DMEM containing $10 \mathrm{ng} / \mathrm{ml}$ IGF1 and 2\% FBS altered the morphology of the myoblasts; they underwent fusion with one another to generate nascent myotubes (Fig. 2D). Quantitative analyses of 4 slides were performed at each step during the 


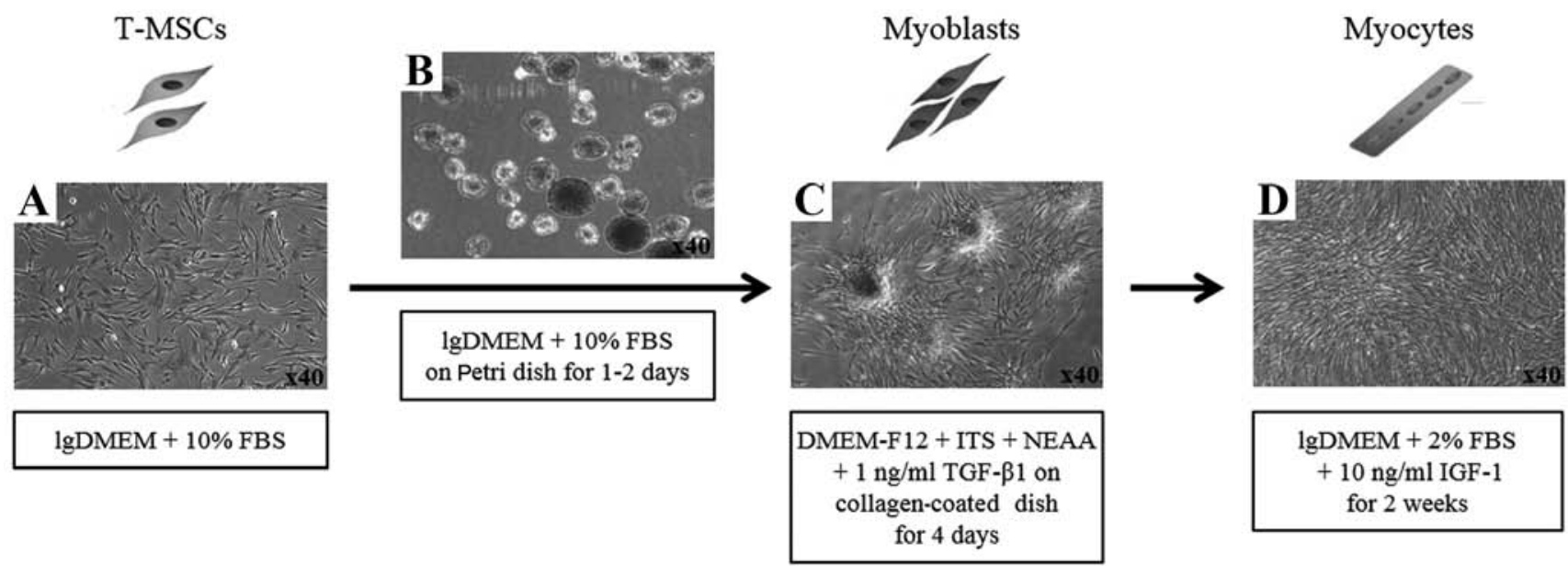

Figure 2. Schematic of myogenic differentiation from human tonsil-derived mesenchymal stem cells (T-MSCs). (A) The undifferentiated T-MSCs were induced to form (B) spheres of approximately 50-100 $\mu \mathrm{m}$ in diameter on a Petri dish. (C) The T-MSCs grew out of the sphere when transferred to the collagen-coated dish in the replating medium and formed a rosette-like spread. (D) The plated cells were cultured for 2 weeks in myogenic induction medium and their morphology was altered; they underwent fusion with one another to generate nascent myotubes. Original magnification, $\mathrm{x} 40$. lgDMEM, low-glucose DMEM; NEAA, non-essential amino acids; ITS, insulin-transferrin-selenium.

process of myogenic differentiations, the $\operatorname{Pax} 7$ and $\alpha$-actinin positive cells were counted, respectively.

T-MSCs express muscle-related genes under conditions that induce myogenic differentiation. We performed RT-PCR to determine whether T-MSCs are capable of expressing myogenic markers and of undergoing myogenic differentiation in vitro. Myogenesis is accompanied by the induction of myogenic markers, including myogenin and dystrophin, at the expense of pluripotency-coupled genes (31-33), suggesting that the T-MSCs have differentiated into myogenic cells. In particular, we found that Pax7 and Myf6, which play a role in myogenesis through the regulation of muscle precursor cell proliferation (34), were already expressed in the undifferentiated T-MSCs (Fig. 3A). These results show that T-MSCs possess characteristics of myogenic precursor cells. The mRNA expression levels of pluripotent markers, namely Klf4, Rexl, and activin were upregulated in the undifferentiated T-MSCs and myoblasts, which have a greater ability to proliferate than myogenic cells. Western blot analysis revealed higher expression levels of desmin and $\alpha$-SMA at the differentiation stage (Fig. 3B; lanes $b$ and $\mathrm{c}$ ). The expression of $\alpha$-actinin was similar at all stages of differentiation (Fig. 3B). The expression of the skeletal myogenic markers, TNNI1 and myogenin, was similar in the myoblasts and the myocytes (Fig. 3B; lanes b and c). Consistent with these results, immunostaining of the multinucleated structures revealed the presence of desmin, $\alpha$-actinin, TNNI1 and myogenin (Fig. 4). These results indicate that T-MSCs possess the characteristics of myogenic precursor cells and also possess a high capacity to undergo myogenic differentiation.

Detection of myogenic markers by immunostaining in vitro. To determine the phenotypes of the cells within the spheres and of the T-MSCs, and to measure the innate ability of the MSCs to differentiate into SKM cells, we replated the spheres onto coverslips in order to allow differentiation into myoblasts and skeletal myogenic cells and sequentially cultured them in myogenic differentiation medium (Fig. 2). These cells were then fixed and labeled with antibodies against markers of myogenic satellite cells (CD34), precursors (Pax7), differentiated myogenic cells (desmin, dystrophin and MHC) and skeletal myogenic cells ( $\alpha$-actinin, TNNI1 and myogenin). Although CD34 (red) and Pax7 (green) were expressed in the undifferentiated T-MSCs (Fig. 4A, panels a and b), the markers of myogenic cells and skeletal myocytes were not. These results indicate that T-MSCs possess pre-existing myogenic characteristics. Following differentiation into myoblasts, $80-90 \%$ of cells expressed desmin (red), dystrophin (green) and MHC (red) (Fig. 4B, panels c to e and Fig. 5) and 20-50\% of cells expressed SKM markers [( $\alpha$-actinin (green), TNNI1 (green) and myogenin (red)] (Fig. 4B, panels $\mathrm{f}$ to $\mathrm{h}$ and Fig. 5). By contrast, the markers of myogenic satellite and precursor cells, CD34 and Pax7, were not expressed during the differentiation of T-MSC-derived myoblasts to T-MSC-derived myocytes (Fig. 4B and $\mathrm{C}$, panels a and b). Furthermore, the T-MSC-derived myocytes exhibited an increased expression of the myogenic and the SKM markers compared with the T-MSC-derived myoblasts or the undifferentiated T-MSCs (Fig. 4A-C, panels $\mathrm{c}$ to $\mathrm{h}$ ).

Alterations occurring within the myogenic cell population during differentiation in vitro. To demonstrate the potential of T-MSCs for skeletal myogenic differentiation, the number of $\mathrm{Pax}^{+}$and $\alpha$-actinin ${ }^{+}$cells was counted at each stage of the differentiation process (Fig. 6). The proportion of Pax $7^{+}$cells among the myogenic satellite and precursor cells was $39.9 \%$ prior to differentiation, whereas the proportion of $\mathrm{Pax} 7^{+}$cells among the T-MSC-derived myoblasts and myocytes was $<1 \%$ (Fig. 6A and B). Moreover, the percentages of cells containing the SKM structural protein, $\alpha$-actinin ${ }^{+}$, were 5.2 and $34.5 \%$ in the myoblasts and myocytes, respectively. However, the proportion of $\alpha$-actinin ${ }^{+}$cells in the undifferentiated T-MSCs was $<1 \%$ (Fig. 6A and B).

T-MSCs participate in SKM regeneration in vivo. We analyzed the effects of T-MSC engraftment in order to assess the regeneration of injured muscle in mice 2 days, 1 week, 4 and 

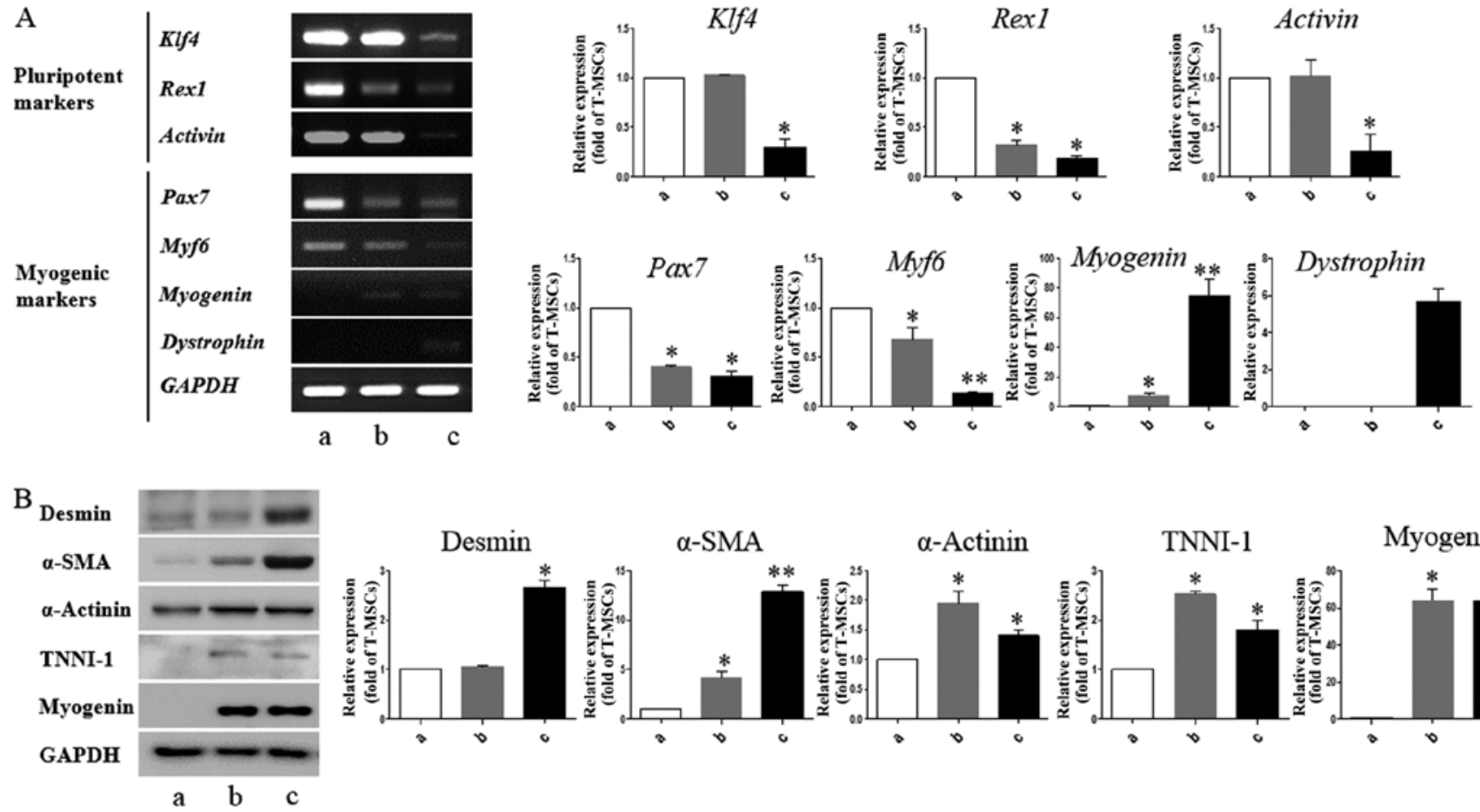

Figure 3. Detection of myogenic markers in tonsil-derived mesenchymal stem cell (T-MSC)-derived myogenic cells. (A) Determination of the mRNA expression levels of pluripotent and myogenic markers. mRNA was isolated from (lane a) undifferentiated T-MSCs, (lane b) T-MSC-derived myoblasts cultured in replating medium as rosette-like spread spheres, and (lane c) terminally differentiated T-MSC-derived myocytes and the cells were examined by RT-PCR. (B) Protein expression levels of myogenic markers in T-MSCs during the process of myogenic induction (lane a, T-MSCs; lane b, T-MSC-derived myoblasts; lane c, T-MSCderived myocytes). The levels of GAPDH were measured as a loading control. Band intensities were quantified using ImageJ software. Data are the means \pm SEM of experiments performed in triplicate. " $\mathrm{P}<0.05 ;{ }^{* *} \mathrm{P}<0.01$. Klf4, Krüppel-like factor 4; Pax7, paired box 7; Myf6, myogenic factor 6; $\alpha$-SMA, $\alpha$-smooth muscle actin; TNNI1, troponin I type 1; GAPDH, glyceraldehyde 3-phosphate dehydrogenase.
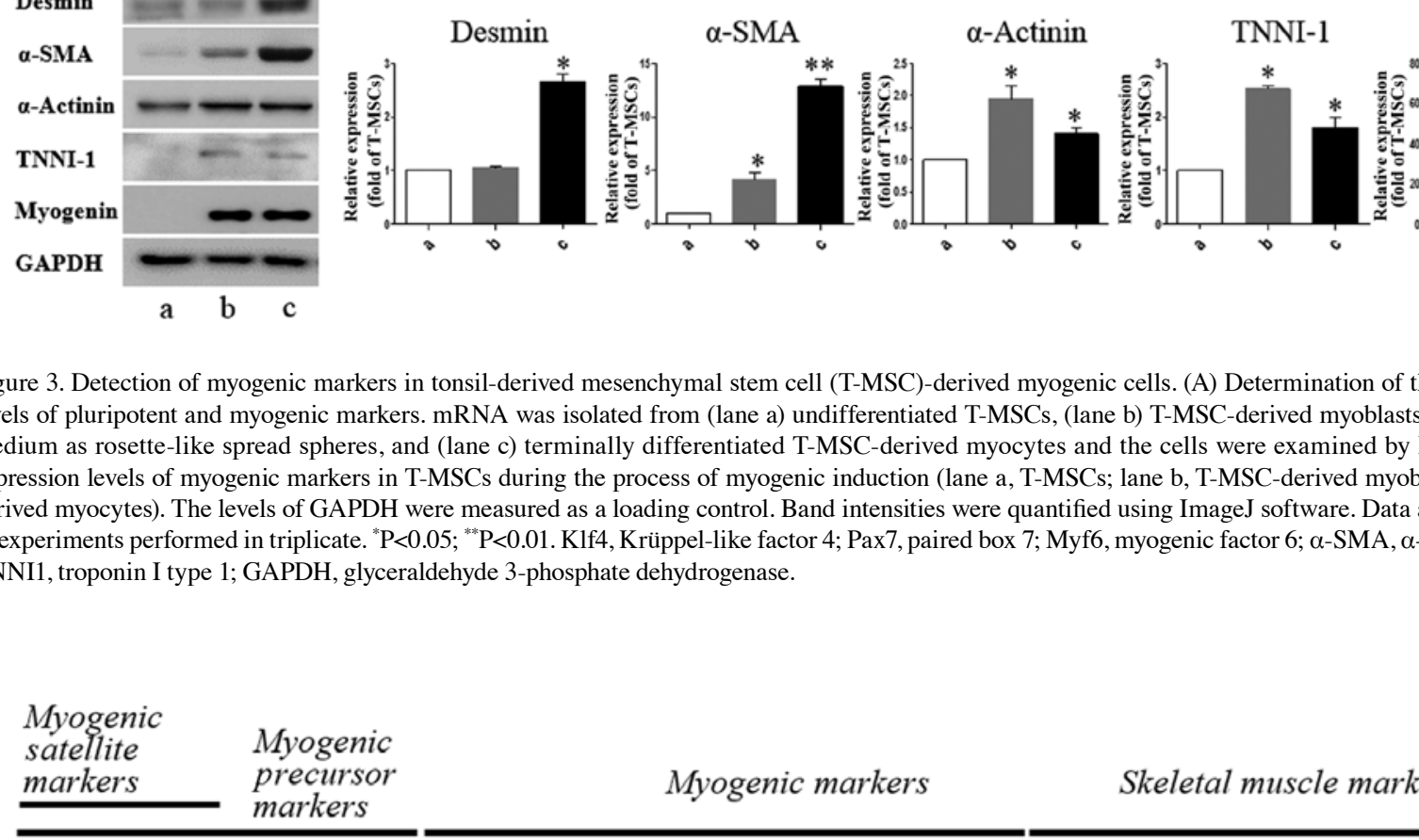

Myogenin

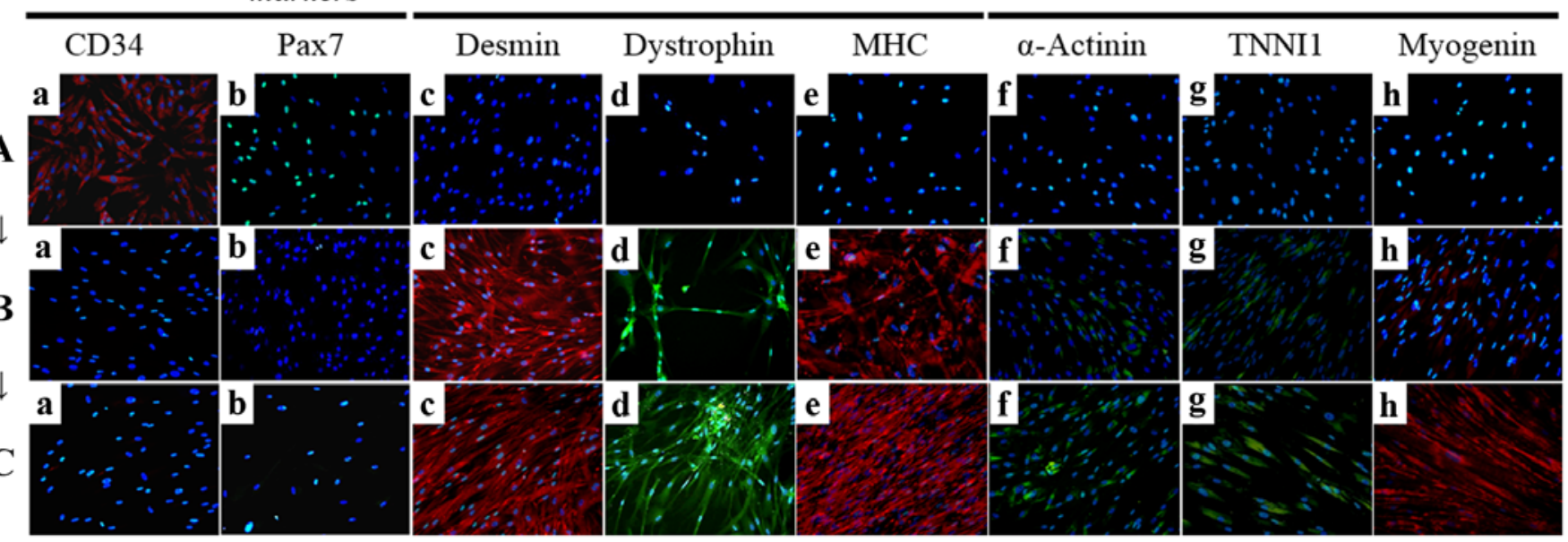

Figure 4. Immunocytochemistry for the detection of myogenic markers. The expression of muscle-related proteins in the tonsil-derived mesenchymal stem cells (T-MSCs) during the process of myogenic induction (T-MSCs; T-MSC-derived myoblasts; T-MSC-derived myocytes) was evaluated by immunostaining using antibodies against myogenic satellite cells (panel a, CD34; red), precursors [panel b, paired box 7 (Pax7); green], differentiated myogenic cells [panel c, desmin (red); panel d, dystrophin (green); panel e, myosin heavy chain (MHC; red)], skeletal myogenic cells [panel f, $\alpha$-actinin (green); panel g, troponin I type 1 (TNNI1; green); panel h, myogenin (red)]. The cells were counterstained with DAPI (blue). The samples were analyzed under a fluorescence microscope using appropriate filters. (A) Undifferentiated T-MSCs expressed (panel a) CD34 and (panel b) Pax7, but no other markers of myogenic cells. (B) Following differentiation into myoblasts, 80-90\% of cells expressed (panel c) desmin, (panel d) dystrophin, and (panel e) MHC and 20-50\% of cells expressed skeletal muscle (SKM) markers including (panel f) $\alpha$-actinin, (panel g) TNNI1, and (panel h) myogenin. (Panel a) CD34 and (panel b) Pax7 were not expressed at any stage of the differentiation process from T-MSC-derived myoblasts into T-MSC-derived myocytes. (C) T-MSC-derived myocytes exhibited an increased expression of (panels $\mathrm{c}$ to h) myogenic and SKM cell markers compared with T-MSC-derived myoblasts and formed multinucleated myotubes. FITC, fluorescein isothiocyanate; TRITC, tetramethylrhodamine isothiocyanate. Original magnification, $\mathrm{x} 200$. 


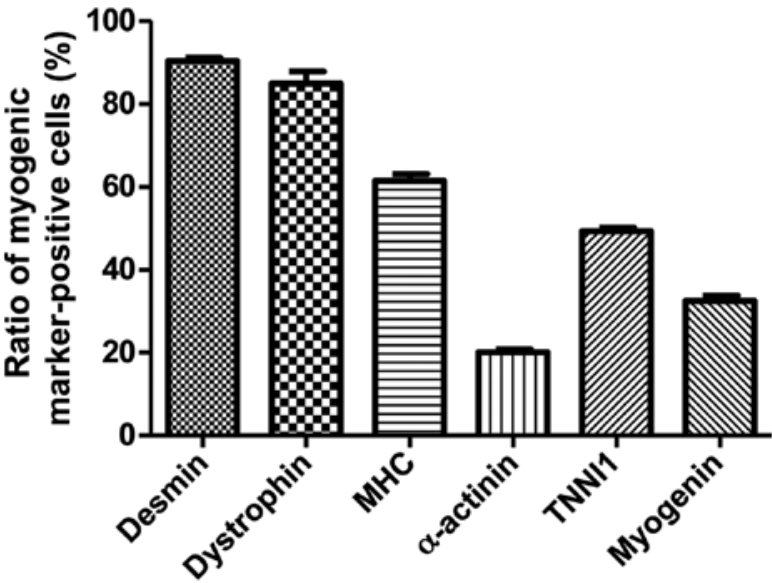

Figure 5. Quantification of immunofluorescence staining confirmed that during the process of myogenic differentiation, the expression of the myogenic markers, indicating the differentiation potential of T-MSCs to form myoblasts. Data are the means \pm SEM. For each condition, 4 slides were used for quantification. Graphs represent the average of multiple tests from 3 independent experiments.

8 weeks post-transplantation. The muscles of the injured mice and the PBS-injected (vehicle-treated) control mice exhibited no expression of $\alpha$-SMA (green) at 2 days to 4 weeks (Fig. 7A, $\mathrm{B}, \mathrm{E}, \mathrm{F}, \mathrm{I}$ and J); however, $\alpha$-SMA was expressed at a low level at 8 weeks (Fig. 7M and N) post-transplantation. A high expression of $\alpha$-SMA was observed at 1-8 weeks in the muscles of mice injected with the T-MSC-derived myocytes (Fig. 7H, L and $\mathrm{P}$ ), whereas the expression of $\alpha$-SMA in the T-MSC-injected muscles was low at 4-8 weeks (Fig. $7 \mathrm{~K}$ and $\mathrm{O}$ ) post-transplantation. There was a minimal expression of dystrophin (red) in the muscles of the injured mice and the vehicle-treated mice (Fig. 7A, B, E, F, I, J, M and N), whereas dystrophin expression was detected as early as 2 days post-transplantation in the muscles of mice injected with T-MSCs and T-MSC-derived myocytes (Fig. 7C, D, G, H, L, O and P). Dystrophin is a protein located between the sarcolemma that supports muscle fiber strength, and the absence of dystrophin reduces muscle stiffness (35). These results demonstrated that the T-MSC-derived myocytes enhanced the generation of newly formed myofibers, which expressed $\alpha$-SMA and dystrophin from 1 week posttransplantation. In addition, the expression of TNNI1 (red), the human SKM troponin gene, was increased post-transplantation concomitantly with the regeneration process (Fig. 8C, D, G, H, $\mathrm{K}, \mathrm{L}, \mathrm{O}$ and $\mathrm{P}$ ). Particularly, more intense staining for TNNI1 was observed post-transplantation with the T-MSC-derived myocytes than with the T-MSCs (Fig. 8D, H, L and P). Similarly to $\alpha$-SMA and dystrophin, TNNI1 was minimally expressed in the muscles of the injured and the vehicle-treated mice (Fig. 8A, B, E, F, I, J, M and N).

Attenuation of motor deficits following the transplantation of T-MSC-derived myocytes in mice with a partial myectomy of the gastrocnemius muscle. To determine whether the engraftment of T-MSC-derived myoblasts or myocytes ameliorates muscle function following injury, we measured the stride length of mice subsequent to a partial myectomy of the right gastrocnemius muscle and T-MSC-derived myogenic cell engraftment. Gait assessment was carried out by footprint analysis, as described in the Materials and methods at 1,2,3,4 and 8 weeks posttransplantation (Fig. 9). The stride distances were markedly reduced in the injured and PBS-injected (vehicle-treated) mice at 1 week after the myectomy. The stride lengths of the mice injected with the T-MSC-derived myocytes were significantly increased at 2, 3, 4 and 8 weeks post-transplantation $(\mathrm{P}<0.01$ $0.05)$. No such improvement in stride distance was observed in the injured/vehicle-treated animals. These results indicated that the engraftment of T-MSC-derived myogenic cells improved the functional ability of the mice with a partial myectomy of the right gastrocnemius muscle.

Restoration of SKM by engraftment of the T-MSC-derived myogenic cells. We analyzed the effects of T-MSC engraftment in mice to determine whether it elicited the morphological regeneration of the injured right muscle at 10 weeks post-trans-
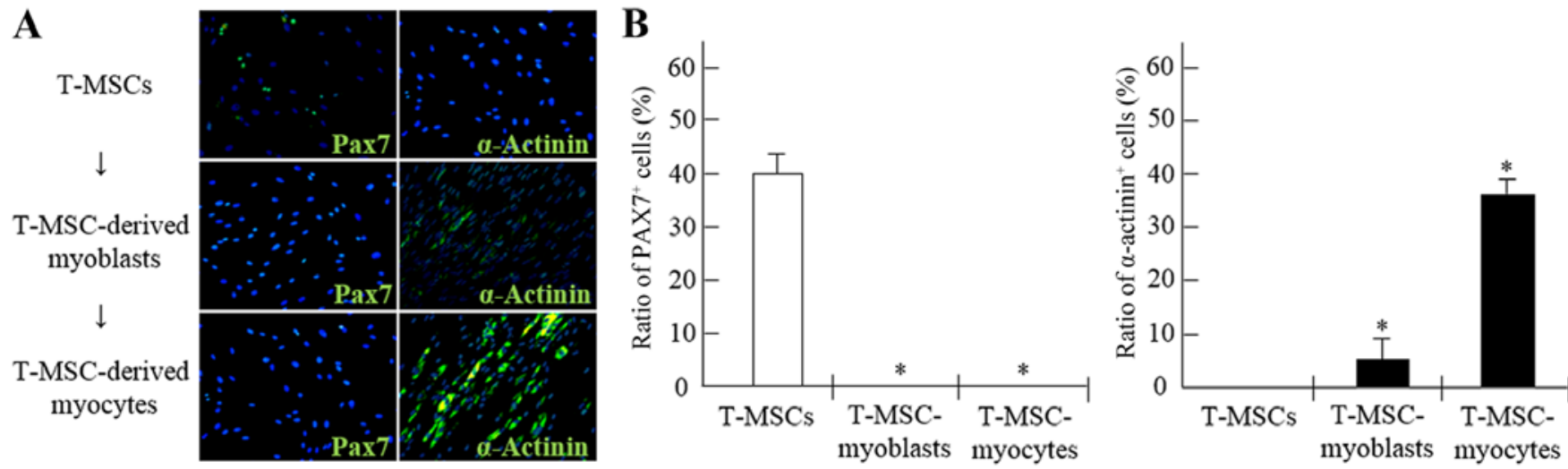

Figure 6. Derivation of myogenic cells from human tonsil-derived mesenchymal stem cells (T-MSCs). (A) The expression of myogenic proteins in T-MSCs during the process of myogenic induction was evaluated by immunostaining using primary antibodies against paired box protein 7 (Pax7; green) or $\alpha$-actinin (green). The cells were counterstained with DAPI (blue). The samples were analyzed under a fluorescence microscope using appropriate filters. (B) Quantification of immunofluorescence confirmed that during the process of myogenic differentiation, the expression of Pax 7 and $\alpha$-actinin was decreased or increased, respectively, indicating the differentiation potential of T-MSCs to form myocytes. Data are the means \pm SEM. For each condition, 4 slides were used for quantification. Graphs represent the average of multiple tests from three independent experiments, ${ }^{*} \mathrm{P}<0.05$. FITC, fluorescein isothiocyanate. Original magnification, $\mathrm{x} 200$. 


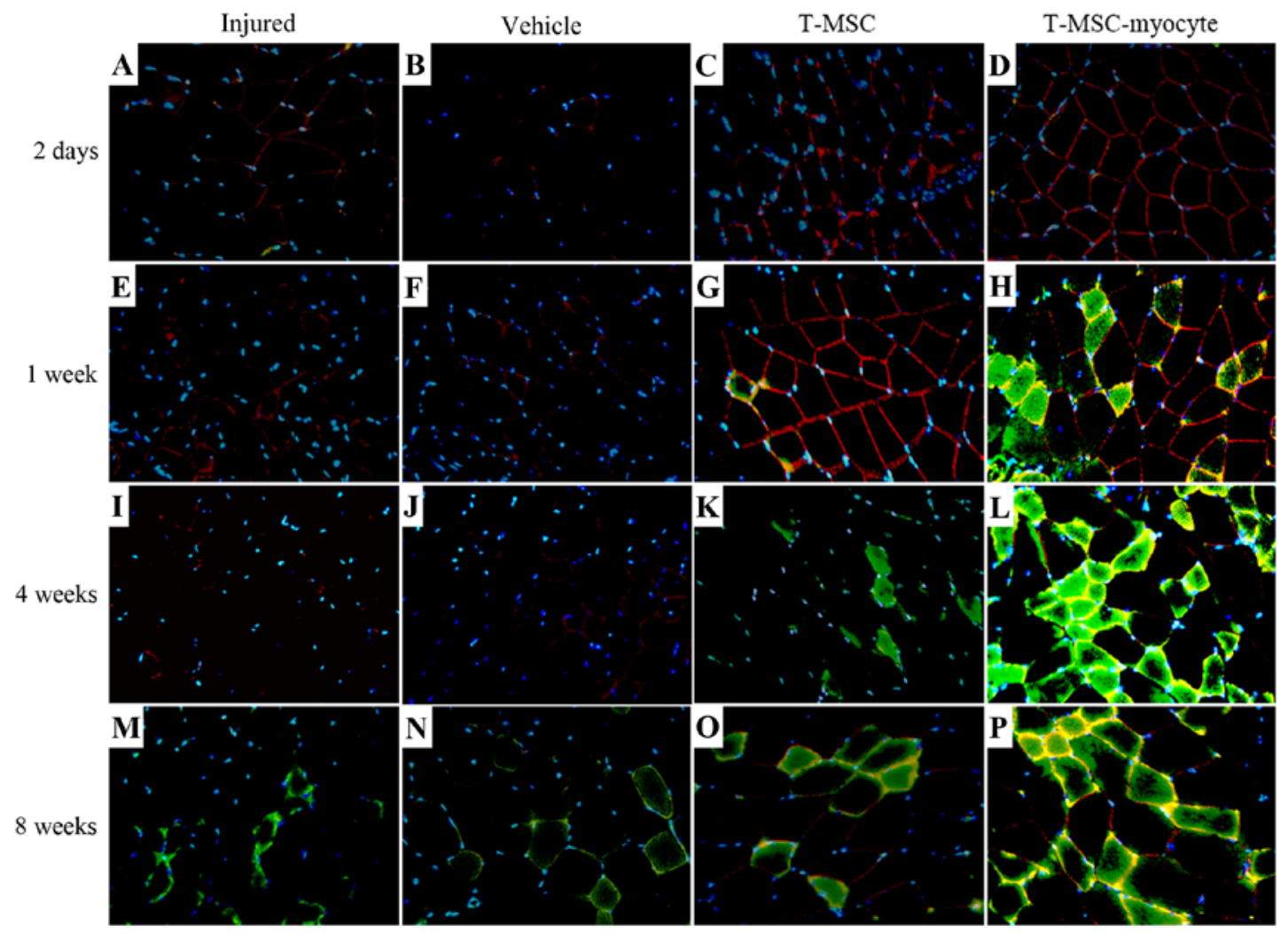

Figure 7. Regenerative potential of human tonsil-derived mesenchymal stem cells (T-MSCs) transplanted into myectomized C57BL/6 mice. Forty-eight hours after muscle injury, T-MSCs or T-MSC-derived myogenic cells were injected intramuscularly into the midpoint of the damaged part of the gastrocnemius muscle. DAPI staining (blue), immunostaining for $\alpha$ smooth muscle actin ( $\alpha$-SMA; green), dystrophin (red); for $\alpha$ smooth muscle actin ( $\alpha$-SMA; green), dystrophin (red); yellow-orange colours indicate the merged images of $\alpha$-SMA and dystrophin. Original magnification, $x 400$.

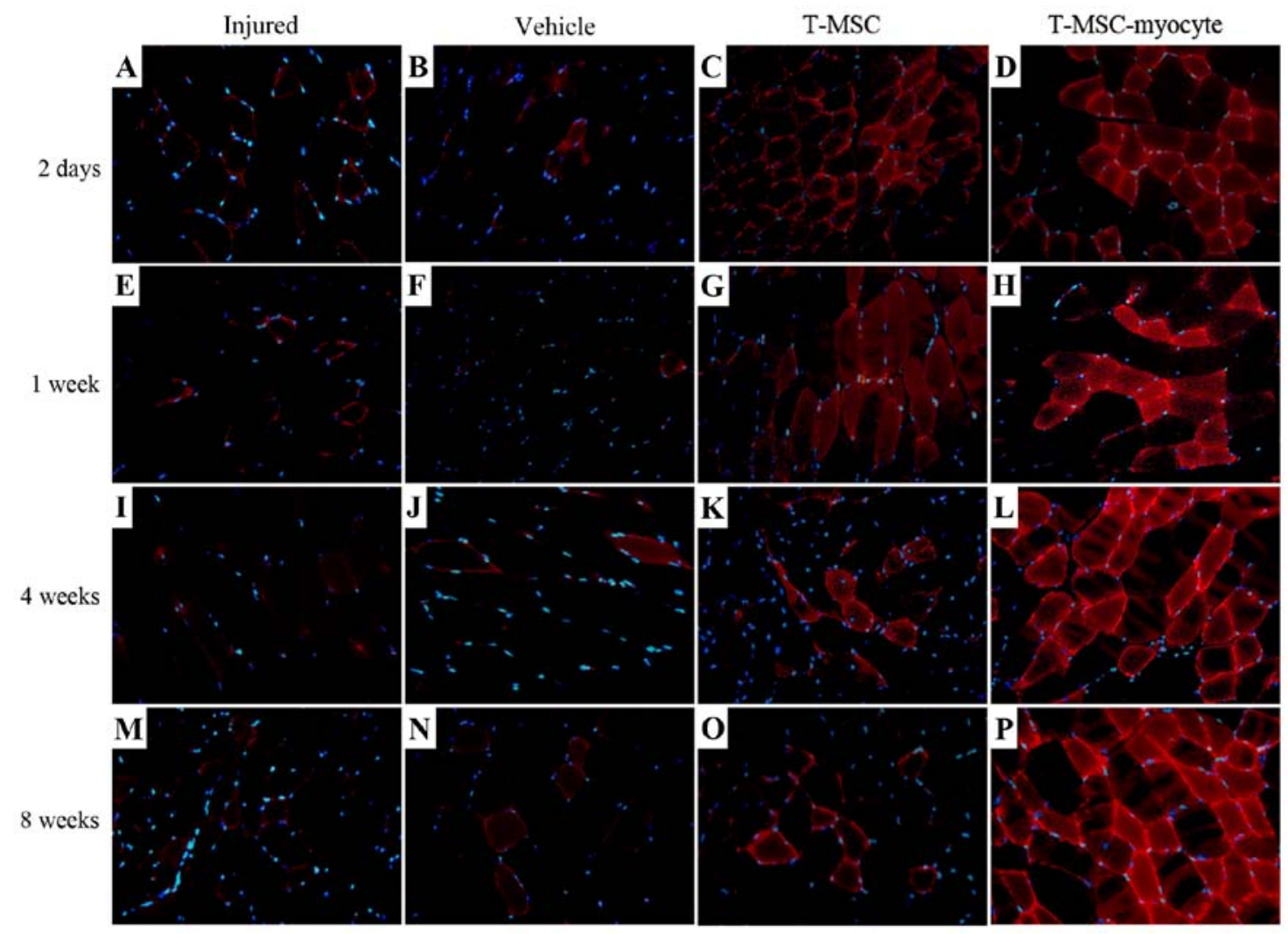

Figure 8. Skeletal muscle (SKM) regeneration of human tonsil-derived mesenchymal stem cells (T-MSCs) transplanted into myectomized C57BL/6 mice. Following muscle injury, T-MSCs or T-MSC-derived myogenic cells were injected intramuscularly and biopsy specimens were obtained at 2 days and 1, 4 and 8 weeks post-transplantation. Representative images of SKM regeneration showing troponin I type 1 (TNNI1; red) and DAPI (blue) staining on a tissue crosssection from mice in the injured, vehicle-treated (vehicle) and T-MSC- and T-MSC myocyte-injected groups. Original magnification, $\mathrm{x} 400$. 

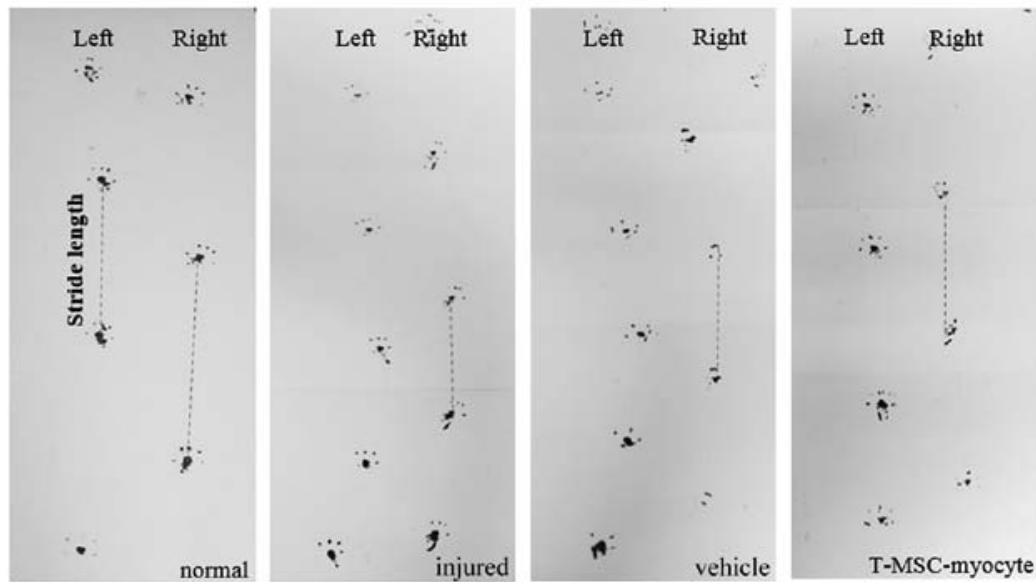

B
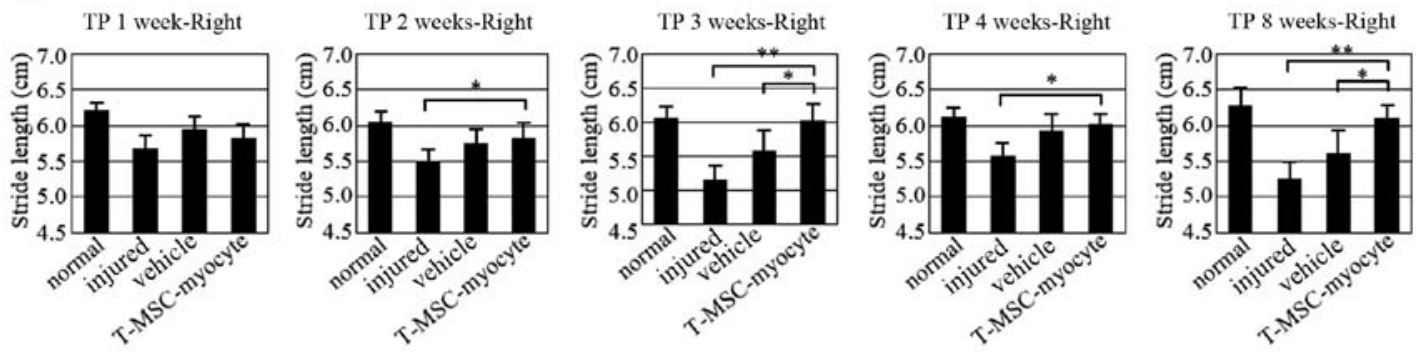

Figure 9. Assessment of gait by footprint analysis. (A) Parameters measured in footprint analysis are shown, with dotted lines representing the direction of progression. Footprinting of normal $(\mathrm{n}=8)$ and injured $(\mathrm{n}=8)$, sham $(\mathrm{n}=8)$, and myocyte-injected mice $(\mathrm{n}=8)$ evaluated at $1,2,3,4$ and 8 weeks post-transplantation for the measurement of stride length $(\mathrm{cm})$. (B) Histograms represent differences in stride length among the normal, injured and vehicle-treated mice as well as mice injected with T-MSC-derived myocytes. Graphs represent the average of multiple tests from three independent experiments, ${ }^{*} \mathrm{P}<0.05$, ${ }^{* *} \mathrm{P}<0.01$. TP, transplantation.

plantation. The muscles from the injured and the vehicle-treated mice (Fig. 10B and C) exhibited signs of injury at 10 weeks, whereas the damage at 1 week was severe in the injured mice (Fig. 10A). By contrast, no sign of injury was apparent in the engrafted mice (Fig. 10D-F) at 10 weeks post-transplantation. Uniquely, the shape of the gastrocnemius muscle mass was restored in the T-MSC-injected mice (Fig. 10D); the stride length of the T-MSC-injected mice was not measured due to no enhancement of regeneration in the immunostaining. These changes in the shape of the gastrocnemius muscle confirmed the results of immunostaining and the gait assessment analysis, demonstrating that the T-MSC-derived myogenic cells promoted the regeneration of SKM.

\section{Discussion}

Adult stem cells derived from older individuals have a reduced ability to proliferate, migrate and secrete cytokines or growth factors than stem cells derived from young individuals $(18,36)$. Therefore, there is a need to obtain cells from alternative sources, such as the tonsils which are removed from younger individuals and are subsequently discarded. Recent studies have also demonstrated that T-MSCs not only readily differentiate into mesodermal tissue cells, including adipocytes, osteocytes and chondrocytes (17,21), but also into hepatocytes (20), endothelial cells (24) and dermal fibroblasts (37). T-MSCs may differentiate into cells of all 3 germ layers, namely the endoderm, mesoderm and ectoderm. In this study, we demonstrated that undifferentiated T-MSCs possess pre-existing characteristics of myosatellite cells and a high capacity to differentiate into skeletal myocytes. For these reasons, we suggest that T-MSCs are a more suitable source of cells for myogenesis and the regeneration of SKM than other types of MSCs.

TGF- $\beta$ profoundly influences the differentiation of many cell types of mesenchymal origin, including preadipocytes $(38,39)$, osteoblasts (40) and myoblasts (41). In previous studies on cultured myoblasts, TGF- $\beta$ was shown to inhibit the expression of musclespecific genes, as well as myotube formation without affecting cell proliferation $(42,43)$. Due to these findings, in our study, $1 \mathrm{ng} / \mathrm{ml}$ TGF- $\beta$ was only added to the medium in order to induce the differentiation of the cells into myoblasts (Fig. 2C). During vertebrate embryogenesis, mesodermal progenitors give rise to distinct mesenchymal lineages, including skeletal myocytes, osteocytes, chondrocytes and adipocytes. The commitment and subsequent differentiation of an MSC toward a particular lineage is regulated by the coordinated action of several extracellular signals, some of which, for example IGF1, are shared by adipocytes and myocytes and may promote the production of one or the other cell type (44). Insulin may also bind to the IGF1 receptor and IGF1 may bind to the insulin receptor; furthermore, IGF1/ insulin hybrid receptors are present in SKM. However, insulin is particularly important in glucose homeostasis, whereas IGF1 is principally involved in muscle growth (45). The systemic administration of IGF1 results in increased muscle protein content and reduced protein degradation (46). The stimulatory effect of IGF1 on the proliferation of myofibroblasts and the deposition of extracellular matrix may interfere with the ability of this growth factor, even at high concentrations, to promote muscle healing 

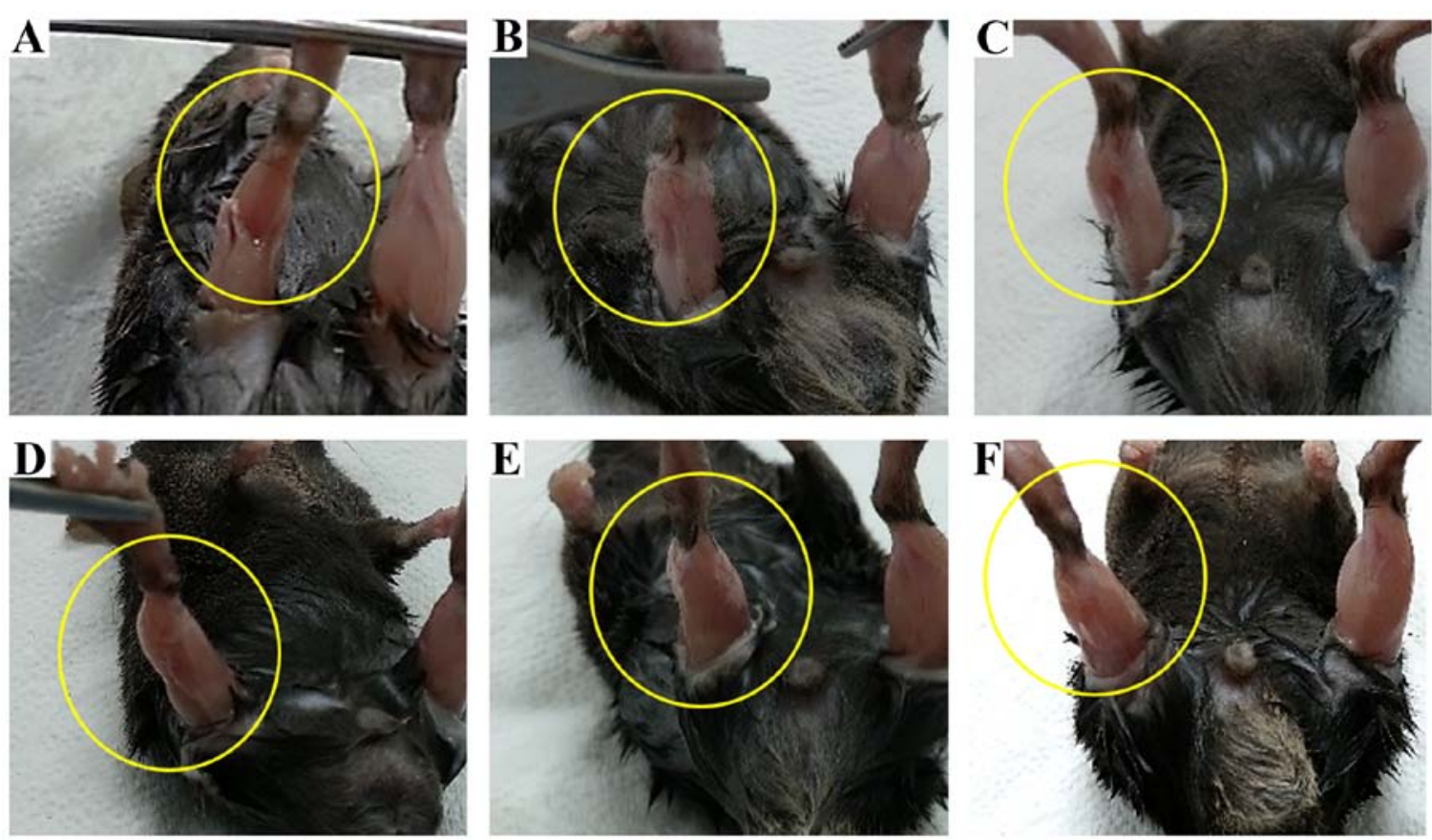

Figure 10. Morphology of the gastrocnemius muscle in mice. The shape of the muscle changed following engraftment. Photographs showing the muscles of the injured mice at (A) 1 week and (B) 10 weeks post-transplantation. Photographs showing the muscles of a (C) vehicle-treated mouse, (D) tonsil-derived mesenchymal stem cell (T-MSC)-injected mouse, (E) T-MSC-derived myoblast-injected mouse, and (F) T-MSC-derived myocyte-injected mouse at 10 weeks post-transplantation.

following injury (47). In this study, $10 \mathrm{ng} / \mathrm{ml} \mathrm{IGF} 1$ was used in the myogenic induction medium in order to induce terminal myogenic differentiation (Fig. 2D).

To induce the myogenic differentiation of T-MSCs, two steps of differentiation procedures, differentiation into myoblasts and myocytes, were used with different media, respectively. The expression of myogenic markers, such as myogenin, dystrophin, $\alpha$-actinin, and TNNI1 indicated that a substantial proportion of the T-MSCs in the culture were committed to the myogenic differentiation pathway. The T-MSC-derived myoblasts fused to form partial myotubes in vitro. As the T-MSC derivatives were shown to express myogenic markers both before (as myoblasts) and after their incorporation into myotubes, we assume that the inductive signals exist both outside and inside myotubes. In addition, when these cells were transplanted, they supported a complete process of myogenesis, allowing the regeneration of myofibers. Following transplantation, only a small percentage of T-MSC derivatives expressed human-specific markers such as human nuclei (HN; data not shown). The reason for the lack of $\mathrm{HN}$ expression in the majority of T-MSC derivatives remains unclear.

To examine the process of muscle regeneration in a controlled and reproducible way, it was necessary to develop an experimental model of muscle injury (26). A number of studies using various experimental models of injury, including the injection of myotoxic agents (9), crush injury (48), ischemia (12), denervation (49) and muscular dystrophy (13), have demonstrated the unique ability of SKM to regenerate, irrespective of the precise method used to induce the initial injury (50). In this study, we performed a surgical myectomy to establish a novel mouse model of SKM injury in order to mimic a severe loss of muscle mass.
As evidenced by this study, the T-MSC-derived myogenic cells were capable of restoring injured SKM tissue and regenerating the muscle. The defect was either repaired or a gradual remodeling occurred, such that the original defect area was difficult to define by 10 weeks post-transplantation. However, repair of the injury was apparent in the mice transplanted with T-MSC-derived cells (Fig. 10D-F) at 10 weeks post-transplantation. In another study using MyoD-transduced human amniotic fluid stem cells which were transplanted into the injured tibialis anterior muscle of mice, the muscle tissue area was found to be larger than that of injured untreated mice or or PBS-injected control mice (14). Furthermore, Merritt et al (51) demonstrated the ability of a muscle extracellular matrix to support muscle and blood vessel regeneration; however, but full recovery of function does not occur after 42 days (51). In our study, we demonstrated that the transplantation of T-MSC-derived myogenic cells promoted the regeneration of the injured SKM. However, further studies are warranted to determine whether functional recovery also occurs and the number and size of the myofibers also needs to be measured to fully determine the functional outcome.

A number of studies have exploited ES/iPS cells and muscle stem cell therapy in order to promote SKM regeneration $(4,6,7,9,10)$. Although ES/iPS cells have potential, they are associated with inherent limitations, including histocompatibility and ethical concerns. Moreover, although muscle stem cells may be isolated from adult and prenatal tissue, the number of cells that may be harvested is limited. Therefore, adult stem cells, such as MSCs are a suitable source of cells for stem cell therapy, and may be used to promote the regeneration of damaged SKM. In a number of studies, stem cells derived from bone marrow, adipose tissue, the placenta, amniotic fluid, 
umbilical cord blood and urine have shown potential to promote SKM regeneration $(1,11-14,18)$. However, the degree of regeneration obtained when using these cells may be insufficient when the injury or damage is severe $(1,11-14,18)$. T-MSCs may therefore be an excellent choice due to their availability and their myogenic differentiation capacity. Our data demonstrated that T-MSCs have a remarkable capacity for efficient SKM regeneration at 8 weeks post-transplantation, as demonstrated by a gait assessment test.

In conclusion, in this study, we demonstrated that myoblasts may be derived from human T-MSCs and can differentiate into myocytes in vitro. This myogenic differentiation was accompanied by the ability to induce an improvement in stride length of mice with injured SKM, as shown by a gait assessment test. T-MSCs have myogenic potential and may thus promote muscle regeneration through either direct de novo muscle differentiation or by a paracrine mechanism. The functional improvements afforded by the T-MSC-derived myogenic cells are potentially useful in the treatment of human SKM injuries and for damage caused by other degenerative disorders, including congenital defects, trauma, or tumor removal.

\section{Acknowledgements}

This study was supported by grant no. HI12C0135 from the Korean Health Technology R\&D Project, Ministry of Health and Welfare, Republic of Korea and RP-Grant 2014 from Ewha Womans University.

\section{References}

1. Chen W, Xie M, Yang B, Bharadwaj S, Song L, Liu G, Yi S Ye G, Atala A and Zhang Y: Skeletal myogenic differentiation of human urine-derived cells as a potential source for skeletal muscle regeneration. J Tissue Eng Regen Med: Jun 19, 2014 (Epub ahead of print). doi: 10.1002/term.1914.

2. Desai VD, Hsia HC and Schwarzbauer JE: Reversible modulation of myofibroblast differentiation in adipose-derived mesenchymal stem cells. PLoS One 9: e86865, 2014.

3. Gunetti M, Tomasi S, Giammò A, Boido M, Rustichelli D, Mareschi K, Errichiello E, Parola M, Ferrero I, Fagioli F, et al: Myogenic potential of whole bone marrow mesenchymal stem cells in vitro and in vivo for usage in urinary incontinence. PLoS One 7: e45538, 2012.

4. Hosoyama T, McGivern JV, Van Dyke JM, Ebert AD and Suzuki M: Derivation of myogenic progenitors directly from human pluripotent stem cells using a sphere-based culture. Stem Cells Transl Med 3: 564-574, 2014.

5. Pereira T, Gärtner A, Amorim I, Armada-da-Silva P, Gomes R, Pereira C,França ML,Morais DM, Rodrigues MA,Lopes MA, etal: Biomaterials and stem cell therapies for injuries associated to skeletal muscular tissues. In: Advances in Biomaterials Science and Biomedical Applications. Pignatello R (ed). InTech, Rijeka, pp329-355, 2013.

6. Kang JS and Krauss RS: Muscle stem cells in developmental and regenerative myogenesis. Curr Opin Clin Nutr Metab Care 13: 243-248, 2010.

7. Motohashi N, Asakura Y and Asakura A: Isolation, culture, and transplantation of muscle satellite cells. J Vis Exp 86: e50846, 2014.

8. Shi X and Garry DJ: Muscle stem cells in development, regeneration, and disease. Genes Dev 20: 1692-1708, 2006.

9. Darabi R, Gehlbach K, Bachoo RM, Kamath S, Osawa M, Kamm KE, Kyba M and Perlingeiro RC: Functional skeletal muscle regeneration from differentiating embryonic stem cells. Nat Med 14: 134-143, 2008.

10. Mizuno Y, Chang H, Umeda K, Niwa A, Iwasa T, Awaya T, Fukada S, Yamamoto H, Yamanaka S, Nakahata T and Heike T: Generation of skeletal muscle stem/progenitor cells from murine induced pluripotent stem cells. FASEB J 24: 2245-2253, 2010.
11. Dezawa M, Ishikawa H, Itokazu Y, Yoshihara T, Hoshino M, Takeda S, Ide C and Nabeshima Y: Bone marrow stromal cells generate muscle cells and repair muscle degeneration. Science 309: 314-317, 2005.

12. Di Rocco G, Iachininoto MG, Tritarelli A, Straino S, Zacheo A, Germani A, Crea F and Capogrossi MC: Myogenic potential of adipose-tissue-derived cells. J Cell Sci 119: 2945-2952, 2006.

13. Nunes VA, Cavaçana N, Canovas M, Strauss BE and Zatz M: Stem cells from umbilical cord blood differentiate into myotubes and express dystrophin in vitro only after exposure to in vivo muscle environment. Biol Cell 99: 185-196, 2007.

14. Kim JA, Shon YH, Lim JO, Yoo JJ, Shin HI and Park EK: MYOD mediates skeletal myogenic differentiation of human amniotic fluid stem cells and regeneration of muscle injury. Stem Cell Res Ther 4: 147, 2013.

15. Park S, Kim E, Koh SE, Maeng S, Lee WD, Lim J, Shim I and Lee YJ: Dopaminergic differentiation of neural progenitors derived from placental mesenchymal stem cells in the brains of Parkinson's disease model rats and alleviation of asymmetric rotational behavior. Brain Res 1466: 158-166, 2012.

16. Kerkis I, Kerkis A, Dozortsev D, Stukart-Parsons GC, Gomes Massironi SM, Pereira LV, Caplan AI and Cerruti HF: Isolation and characterization of a population of immature dental pulp stem cells expressing OCT-4 and other embryonic stem cell markers. Cells Tissues Organs 184: 105-116, 2006.

17. Ryu KH, Cho KA, Park HS, Kim JY, Woo SY, Jo I, Choi YH, Park YM, Jung SC, Chung SM, et al: Tonsil-derived mesenchymal stromal cells: evaluation of biologic, immunologic and genetic factors for successful banking. Cytotherapy 14: 1193-1202, 2012

18. Ting CH, Ho PJ and Yen BL: Age-related decreases of serum-response factor levels in human mesenchymal stem cells are involved in skeletal muscle differentiation and engraftment capacity. Stem Cells Dev 23: 1206-1216, 2014.

19. Djouad F, Jackson WM, Bobick BE, Janjanin S, Song Y, Huang GT and Tuan RS: Activin A expression regulates multipotency of mesenchymal progenitor cells. Stem Cell Res Ther 1: 11, 2010.

20. Park M, Kim YH, Woo SY, Lee HJ, Yu Y, Kim HS, Park YS, Jo I, Park JW, Jung SC, et al: Tonsil-derived mesenchymal stem cells ameliorate CCI4-induced liver fibrosis in mice via autophagy activation. Sci Rep 5: 8616, 2015. doi: 10.1038/srep08616.

21. Yu Y, Park YS, Kim HS, Kim HY, Jin YM, Jung SC, Ryu KH and Jo I: Characterization of long-term in vitro culture-related alterations of human tonsil-derived mesenchymal stem cells: role for $\mathrm{CCN} 1$ in replicative senescence-associated increase in osteogenic differentiation. J Anat 225: 510-518, 2014.

22. Park M, Kim YH, Ryu JH, Woo SY and Ryu KH: Immune suppressive effects of tonsil-derived mesenchymal stem cells on mouse bone-marrow-derived dendritic cells. Stem Cells Int 2015: 106540, 2015.

23. Ryu KH, Kim SY, Kim YR, Woo SY, Sung SH, Kim HS, Jung SC, Jo I and Park JW: Tonsil-derived mesenchymal stem cells alleviate concanavalin A-induced acute liver injury. Exp Cell Res 326: 143-154, 2014.

24. Park YS, Hwang S, Jin YM, Yu Y, Jung SA, Jung SC, Ryu KH, Kim HS and Jo I: CCN1 secreted by tonsil-derived mesenchymal stem cells promotes endothelial cell angiogenesis via integrin $\alpha_{v} \beta_{3}$ and AMPK. J Cell Physiol 230: 140-149, 2015.

25. Mauro A: Satellite cell of skeletal muscle fibers. J Biophys Biochem Cytol 9: 493-495, 1961.

26. Chargé SBP and Rudnicki MA: Cellular and molecular regulation of muscle regeneration. Physiol Rev 84: 209-238, 2004.

27. Guide for the Care and Use of Laboratory Animals. 8th edition. National Research Council. The National Academies Press, Washington, DC, 2011.

28. Cho KA, Kim JY, Kim HS, Ryu KH and Woo SY: Tonsil-derived mesenchymal progenitor cells acquire a follicular dendritic cell phenotype under cytokine stimulation. Cytokine 59: 211-214, 2012.

29. D'Hooge R, Hartmann D, Manil J, Colin F, Gieselmann V and De Deyn PP: Neuromotor alterations and cerebellar deficits in aged arylsulfatase A-deficient transgenic mice. Neurosci Lett 273: 93-96, 1999.

30. Fernagut PO, Diguet E, Labattu B and Tison F: A simple method to measure stride length as an index of nigrostriatal dysfunction in mice. J Neurosci Methods 113: 123-130, 2002.

31. Beattie GM, Lopez AD, Bucay N, Hinton A, Firpo MT, King CC and Hayek A: Activin A maintains pluripotency of human embryonic stem cells in the absence of feeder layers. Stem Cells 23: 489-495, 2005. 
32. Carpenter MK, Rosler ES, Fisk GJ, Brandenberger R, Ares X, Miura T, Lucero M and Rao MS: Properties of four human embryonic stem cell lines maintained in a feeder-free culture system. Dev Dyn 229: 243-258, 2004.

33. Nakatake Y, Fukui N, Iwamatsu Y, Masui S, Takahashi K, Yagi R, Yagi K, Miyazaki J, Matoba R, Ko MS and Niwa H: Klf 4 cooperates with Oct3/4 and Sox 2 to activate the Lefty1 core promoter in embryonic stem cells. Mol Cell Biol 26: 7772-7782, 2006.

34. Ropka-Molik K, Eckert R and Piórkowska K: The expression pattern of myogenic regulatory factors MyoD, Myf6 and Pax7 in postnatal porcine skeletal muscles. Gene Expr Patterns 11: 79-83, 2011.

35. García-Pelagio KP, Bloch RJ, Ortega A and González-Serratos H: Biomechanics of the sarcolemma and costameres in single skeletal muscle fibers from normal and dystrophin-null mice. J Muscle Res Cell Motil 31: 323-336, 2011.

36. Hass R, Kasper C, Böhm S and Jacobs R: Different populations and sources of human mesenchymal stem cells (MSC) a comparison of adult and neonatal tissue-derived MSC. Cell Commun Signal 9: 12, 2011.

37. Böttcher-Haberzeth S, Biedermann T, Klar AS, Pontiggia L, Rac J, Nadal D, Schiestl C, Reichmann E and Meuli M: Tissue engineering of skin: human tonsil-derived mesenchymal cells can function as dermal fibroblasts. Pediatr Surg Int 30: 213-222, 2014.

38. Choy L, Skillington J and Derynck R: Roles of autocrine TGF-beta receptor and Smad signaling in adipocyte differentiation. J Cell Biol 149: 667-682, 2000.

39. Ignotz RA and Massagué J: Type beta transforming growth factor controls the adipogenic differentiation of 3T3 fibroblasts. Proc Natl Acad Sci USA 82: 8530-8534, 1985.

40. Centrella M, Horowitz MC, Wozney JM and McCarthy TL: Transforming growth factor-beta gene family members and bone. Endocr Rev 15: 27-39, 1994
41. Olson EN: Proto-oncogenes in the regulatory circuit for myogenesis. Semin Cell Biol 3: 127-136, 1992.

42. Massagué J, Cheifetz S, Endo T and Nadal-Ginard B: Type beta transforming growth factor is an inhibitor of myogenic differentiation. Proc Natl Acad Sci USA 83: 8206-8210, 1986.

43. Olson EN, Sternberg E, Hu JS, Spizz G and Wilcox C: Regulation of myogenic differentiation by type beta transforming growth factor. J Cell Biol 103: 1799-1805, 1986.

44. Sordella R, Jiang W, Chen GC, Curto M and Settleman J: Modulation of Rho GTPase signaling regulates a switch between adipogenesis and myogenesis. Cell 113: 147-158, 2003.

45. Schiaffino S and Mammucari C: Regulation of skeletal muscle growth by the IGF1-Akt/PKB pathway: insights from genetic models. Skelet Muscle 1: 4, 2011.

46. Zdanowicz MM, Moyse J, Wingertzahn MA, O'Connor M, Teichberg S and Slonim AE: Effect of insulin-like growth factor I in murine muscular dystrophy. Endocrinology 136: 4880-4886, 1995.

47. Jones JI and Clemmons DR: Insulin-like growth factors and their binding proteins: biological actions. Endocr Rev 16: 3-34, 1995.

48. Bassaglia Y and Gautron J: Fast and slow rat muscles degenerate and regenerate differently after whole crush injury. J Muscle Res Cell Motil 16: 420-429, 1995.

49. Dedkov EI, Kostrominova TY, Borisov AB and Carlson BM: Reparative myogenesis in long-term denervated skeletal muscles of adult rats results in a reduction of the satellite cell population. Anat Rec 263: 139-154, 2001.

50. Politi PK, Havaki S, Manta P and Lyritis G: Bupivacaine-induced regeneration of rat soleus muscle: ultrastructural and immunohistochemical aspects. Ultrastruct Pathol 30: 461-469, 2006.

51. Merritt EK, Hammers DW, Tierney M, Suggs LJ, Walters TJ and Farrar RP: Functional assessment of skeletal muscle regeneration utilizing homologous extracellular matrix as scaffolding. Tissue Eng Part A 16: 1395-1405, 2010. 